\title{
Randomised controlled trial of the effectiveness of a respiratory health worker in reducing impairment, disability, and handicap due to chronic airflow limitation
}

\author{
Peter Littlejohns, Chloe M Baveystock, Helen Parnell, Paul W Jones
}

\begin{abstract}
A randomised controlled trial was undertaken to determine whether a respiratory health worker was effective in reducing the respiratory impairment, disability, and handicap experienced by patients with chronic airflow limitation attending a respiratory outpatient department. The 152 adults (aged 30-75 years) who participated had a prebronchodilator forced expiratory volume in one second $\left(F E V_{1}\right)$ below $60 \%$ predicted and no other disease. They were randomised to receive the care of a respiratory health worker or the normal services provided by the outpatient department. The respiratory health worker provided health education and symptom and treatment monitoring in liaison with primary care services. After one year there was little difference between the two groups in spirometric values $\left(\mathrm{FEV}_{1}\right.$ and forced vital capacity before and after salbutamol $200 \mu \mathrm{g}$ ), disability (six minute walking distance and paced step test), and handicap (sickness impact profile, hospital anxiety and depression scale). Patients not looked after by the respiratory health worker were more likely to die (relative risk 2.9 (95\% confidence limits $0.8,10.2)$; when age and $F E V$, were controlled for this risk increased to $5.5(95 \%$ confidence limits 1.2, 24.5). Patients looked after by the respiratory health worker attended their general practitioner more frequently and were prescribed a greater range of drugs. This is the third study to have found limited measurable benefit in terms of morbidity from the intervention of a respiratory health worker. This may be due to the ability of such workers to keep frail patients alive.
\end{abstract}

The recent report from the Office of Population Censuses and Surveys estimates that chronic disabling disorders affect up to $14.2 \%$ of adults in Great Britain. ${ }^{1}$ The increasing emphasis on community care ${ }^{2}$ and rationalisation of hospital beds ${ }^{3}$ has led to experiments to investigate more cost effective services for chronic disease. ${ }^{4}$ Nurse specialists have been viewed as an appropriate innovation in some specialties $^{56}$ and it has been suggested that they should be employed to help patients with respiratory disease. ${ }^{7}$ Chronic respiratory disease causes $13 \%$ of adult disability and chronic obstructive airways disease is the major cause. ${ }^{8}$ Initial evaluations of respiratory health workers in the United Kingdom ${ }^{9}$ and the United States $^{10}$ suggested that this approach might be expensive without providing demonstrable benefit. The introduction of a new service for patients with chronic lung disease into the health district of Merton and Sutton in South West London provided an opportunity to assess the role of a nurse specialist. It was agreed that patients helped in the first year of the service would be incorporated into a randomised controlled trial designed to show whether a respiratory health worker was effective in reducing the respiratory impairment, disability, and handicap $^{11}$ experienced by patients with chronic airflow limitation.

\section{Methods}

PATIENTS

Patients with previously documented chronic airflow limitation attending hospital respiratory outpatients clinics in the Merton and Sutton Health District were invited by three chest physicians to participate in the study. To be eligible for inclusion patients had to be aged 30-75 years, have no other major disease, and have a prebronchodilator forced expiratory volume in one second $\left(\mathrm{FEV}_{1}\right)$ less than $60 \%$ predicted. All had to be in a stable state as judged by the patient and physician with no change or perceived need for change in medication for at least six weeks before recruitment. All patients gave informed written consent.

ASSESSMENT

On entry into the study baseline measurements were obtained on two separate days. Patients were assessed for respiratory impairment, disability, and handicap as defined by the Royal College of Physicians report. ${ }^{7}$ On the first day the FEV 1 and forced vital capacity (FVC) were measured with a dry wedge spirometer (Vitalograph) and peak expiratory flow (PEF) with a Wright peak flow 
meter. For each measure the mean of three attempts was recorded before and after inhalation of salbutamol $200 \mu \mathrm{g}$. After inhaling bronchodilator patients performed a six minute walking distance test along a corridor. ${ }^{12}$ Standardised encouragement was given. After a recovery period the patients performed a paced step test. ${ }^{13}$ Arterial oxygen saturation $\left(\mathrm{SaO}_{2}\right)$ was recorded with an ear oximeter (Biox III, Ohmeda).

On a second day patients were visited at home by one of the research workers (CB) and asked to complete four questionnaires, which were presented in a randomised sequence. Three were standard questionnaires-the Medical Research Council chronic bronchitis questionnaire, ${ }^{14}$ the Hospital Anxiety and Depression Scale, ${ }^{15}$ and the Sickness Impact Profile. ${ }^{16}$ The Hospital Anxiety and Depression Scale provides separate scores for anxiety and depression. It was developed for use in physically ill patients, so those psychological symptoms that could be caused by disease are excluded. Scores of $0-7$ are considered normal and 8-10 borderline, and $11+$ represents states of depression or anxiety. The Sickness Impact Profile contains 136 questions grouped into 12 categories (ambulation, mobility, body care, social interaction, communication, alertness, emotions, sleep, eating, work, household management, recreation). Three of the categories may be aggregated into a global physical score and another four into a global psychosexual score. All the categories are aggregated to give a total score-the higher the score the greater the handicap. In addition, a specially designed questionaire on the social circumstances (for example, receipt of benefits) of the patients was completed.

At the beginning of the study patients were issued with a diary card, on which they were requested to record drug prescriptions and visits to the general practitioner or an outpatient clinic and inpatient admissions during the trial period. One year after admission to the trial patients were assessed in the same manner. Patients also completed a satisfaction questionnaire designed for the study. This included questions on satisfaction with level of care, the information given to them, and their knowledge of medication.

\section{INTERVENTION}

Patients were randomly allocated to the intervention group, in which they received the care of the respiratory health worker while continuing with their routine outpatient appointments, or to the non-intervention group, in which they received the normal service provided by the chest clinic. Random numbers were generated by tables in permuted blocks of four stratified by age ( 55 years and above and below 55) and sex. The groups to which successive patients were to be allocated were noted in sealed, numbered envelopes, which were kept centrally. The physician recruiting a patient contacted the controller, who opened the appropriate envelope. The physician was aware which group the patient was in.
Those allocated to receive the intervention received the following from the health worker; (1) health education directed at the patient and the primary care team; (2) monitoring of treatment compliance and optimising treatment by ensuring correct inhalation techniques and supervision of domiciliary oxygen etc; (3) monitoring of the results of spirometry and the patient's symptoms to enable acute exacerbations and worsening heart failure to be detected and treated early; (4) liaison between general practitioner and hospital based services (including the domiciliary physiotherapy service and social services).

\section{ANALYSIS}

The hypothesis under test was that the respiratory health worker would reduce the rate of deterioration in physiological and subjective measures of disease activity. The group attended by the respiratory health worker (the intervention group) was compared with the group who had the normal outpatient facilities (the non-intervention group) at the start of the study and one year later. Characteristics of patients who died during the study or who migrated or were lost to follow up were compared with those of patients who completed the study. The significance of the difference between them was tested by the unpaired $t$ tests for normally distributed data, the MannWhitney test for ordinal data, and the $\chi^{2}$ statistic for nominal data. For determining how individuals changed over the study year and allowing for any minor differences in prognostic factors between the two groups, the value an individual had at the end of the study was subtracted from the value at the beginning for indices of impairment, disability, and handicap. These individual differences were summated and the mean differences (and 95\% confidence intervals) for the intervention and non-intervention groups were compared. Relative risks with $95 \%$ confidence intervals were calculated for death during the study year, the non-intervention group being compared with the intervention group. ${ }^{17}$ As age and impaired pulmonary function are important predictors of mortality, ${ }^{18}$ relative risk was reassessed after these variables had been controlled for by multiple logistic regression. ${ }^{19}$

To identify factors that determined change in the indices of handicap multiple stepwise regression analysis was used with entry criteria set at $p=0.05$. For this analysis the two groups were combined, and the intervention was treated as an independent variable. The relation between impairment, disability, and handicap indices has been described in detail elsewhere. ${ }^{20}$

Pulmonary function was adjusted for age and sex according to regression equations given by Cotes. ${ }^{21}$ We expected that 150 patients recruited during the year would provide an $80 \%$ chance of identifying a difference at the $5 \%$ level of $234 \mathrm{ml}$ in $\mathrm{FEV}_{1}, 4$ on the Sickness Impact Profile scale, 1.8 on the Hospital Anxiety and Depression Scale, and 45 in the six minute walking test. 
Table 1 Characteristics of patients by group at entry into study

\begin{tabular}{|c|c|c|}
\hline & $\begin{array}{l}\text { Intervention group } \\
(n=73)\end{array}$ & $\begin{array}{l}\text { Non-intervention group } \\
(n=79)\end{array}$ \\
\hline $\begin{array}{l}\text { Age (mean }(\mathrm{SD}), \text { years) } \\
\% \text { male } \\
\text { Height (mean }(\mathrm{SD}), \mathrm{cm}) \\
\text { Weight (mean }(\mathrm{SD}), \mathrm{kg}) \\
\text { No }(\%) \text { who had ever smoked } \\
\text { No }(\%) \text { still smoking }\end{array}$ & $\begin{array}{l}62 \cdot 9(7 \cdot 8) \\
67 \\
167 \cdot 9(9 \cdot 0) \\
68 \cdot 5(13 \cdot 8) \\
64(88) \\
17(23)\end{array}$ & $\begin{array}{l}62 \cdot 5(7 \cdot 6) \\
63 \\
167 \cdot 7(9 \cdot 5) \\
70 \cdot 35(16 \cdot 4) \\
68(86) \\
21(27)\end{array}$ \\
\hline $\begin{array}{l}\text { Symptoms (No }(\%)) \\
\text { Cough most days } \\
\text { Produce sputum most days } \\
\text { Short of breath most days } \\
\text { Wheeze most days }\end{array}$ & $\begin{array}{l}33(45) \\
26(36) \\
47(64) \\
18(25)\end{array}$ & $\begin{array}{l}40(51) \\
31(39) \\
55(70) \\
20(25)\end{array}$ \\
\hline $\begin{array}{l}\text { Pulmonary function (mean (SI } \\
\text { FEV }_{1} \\
\mathrm{FVC} \\
\mathrm{SaO}_{2}(\text { mean }(\mathrm{SD}) \%) \\
\text { Rest } \\
\text { Exercise }\end{array}$ & $\begin{array}{l}\text { red) } \\
45 \cdot 2(22 \cdot 4) \\
70 \cdot 0(17 \cdot 3) \\
\\
95 \cdot 6(3 \cdot 0) \\
91 \cdot 5(4 \cdot 6)\end{array}$ & $\begin{array}{l}50 \cdot 2(23 \cdot 0) \\
73 \cdot 2(19 \cdot 0) \\
96 \cdot 1(2 \cdot 7) \\
91 \cdot 7(4 \cdot 3)\end{array}$ \\
\hline $\begin{array}{l}\text { Exercise tests (mean (SD)) } \\
\text { Walking (m) } \\
\text { Step (number) }\end{array}$ & $\begin{array}{r}370 \cdot 6(97 \cdot 2) \\
57 \cdot 1(53 \cdot 1)\end{array}$ & $\begin{array}{c}372 \cdot 4(117 \cdot 6) \\
64 \cdot 3(55 \cdot 0)\end{array}$ \\
\hline $\begin{array}{l}\text { Mood as measured by hospital } \\
\text { and depression scale } \\
\text { Anxiety } \\
\text { Depression }\end{array}$ & $\begin{array}{l}7 \cdot 7(4 \cdot 3) \\
5 \cdot 5(3 \cdot 7)\end{array}$ & $\begin{array}{l}6 \cdot 8(4 \cdot 6) \\
4 \cdot 9(3 \cdot 3)\end{array}$ \\
\hline $\begin{array}{l}\text { Sickness Impact Profile (mean } \\
\text { Total } \\
\text { Physical } \\
\text { Psychosocial }\end{array}$ & $\begin{array}{l}\text { core } \\
\qquad \begin{array}{l}9 \cdot 4(8 \cdot 8) \\
7 \cdot 1(8 \cdot 4) \\
9 \cdot 8(11 \cdot 4)\end{array}\end{array}$ & $\begin{array}{l}7 \cdot 2(7 \cdot 6) \\
5 \cdot 1(7 \cdot 8) \\
7 \cdot 1(8 \cdot 9)\end{array}$ \\
\hline
\end{tabular}

$\mathrm{FEV}_{1}$ - forced expiratory volume in one second; $\mathrm{FVC}$-forced vital capacity; $\mathrm{SaO}_{2}-$ arterial oxygen saturation.

Changes at the $5 \%$ level were considered to be statistically significant.

\section{Results}

CHARACTERISTICS OF PATIENTS

Of the 166 patients recruited, 14 changed their minds before the start of the study. There were 73 patients in the intervention group and 79 patients in the non-intervention group. During the year three patients in the intervention group died and nine in the non-intervention group. In addition, two patients from the intervention group and five from the nonintervention group were lost to follow up: four patients had moved, two patients asked to withdraw, and one patient failed to cooperate. Thus 68 patients in the intervention group and 65 in the non-intervention group completed the study. This represents $80 \%$ of those originally invited to take part and $88 \%$ of those who started in the study. Table 1 shows some of the characteristics of the patients at the beginning of the study. $\mathrm{FEV}_{1}$ was about half that predicted for age, sex, and height.

Patients who died during the study were older (mean (SD) age $62.4(7 \cdot 6)$ years for survivors, 67.3 (5) for patients who died: $\mathrm{p}=<0.05$ ), had worse lung function (mean $\mathrm{FEV}_{1} 49 \%(22 \%)$ predicted in survivors, $33 \%$ $(23 \%)$ in those who died: $\mathrm{p}=<0.01$, and performed less well on the walking test (383 (92) v 250 (16) metres: $p<0.001$ ). Patients who died were more likely to be in the nonintervention group, the relative risk for dying being 2.9 (95\% confidence limits $0.8,10.2)$ by comparison with the intervention group. After $\mathrm{FEV}_{1}$ and age had been controlled for in a single logistic regression model the calculated odds ratio was $5 \cdot 5(95 \% \mathrm{CI} 1 \cdot 2,24 \cdot 5)$.

\section{CHANGES IN IMPAIRMENT, DISABILITY, AND HANDICAP}

Both groups showed some deterioration in mean values of lung function over the study period, though for most measurements the

Table 2 Change in impairment, disability, mood state, and handicap scores over the study period in the intervention and non-intervention groups

Score at the end of the study subtracted from the value at the beginning for each individual; the values were then summated and the mean change and $95 \%$ confidence limits (CL) calculated for each group. The sign of the changes indicates the direction of change, positive sign denoting improvement and a negative sign deterioration.

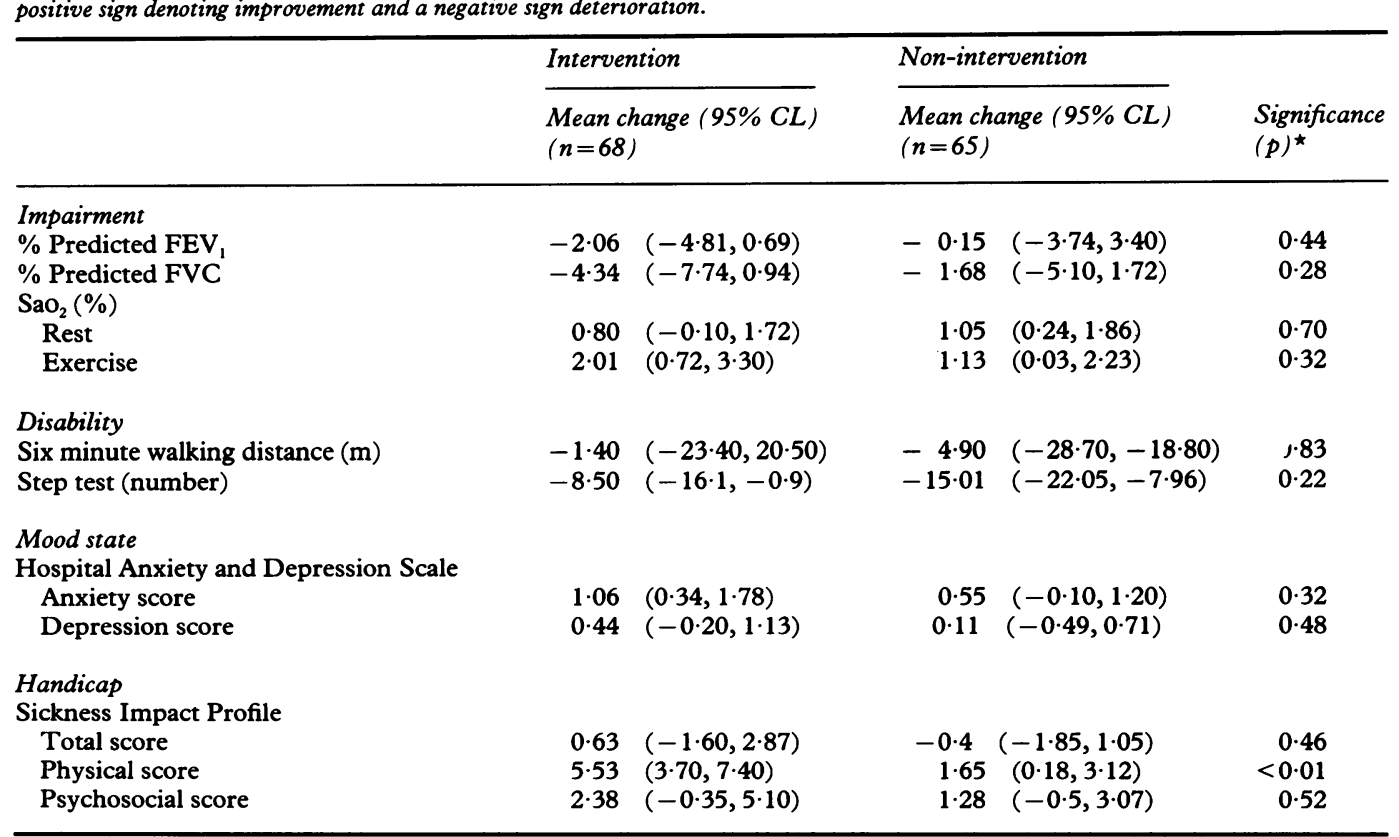

*Unpaired two tailed test of the significance of the difference between mean changes. 
Table 3 Reported drug prescriptions during the study year

\begin{tabular}{|c|c|c|}
\hline \multirow{4}{*}{$\begin{array}{l}\text { Bronchodilator inhaler } \\
\text { Aminophylline }\end{array}$} & \multicolumn{2}{|l|}{ No $(\%)$ of patients } \\
\hline & $\begin{array}{l}\text { Intervention group } \\
(n=68)\end{array}$ & $\begin{array}{l}\text { Non-intervention group } \\
(n=65)\end{array}$ \\
\hline & $62 \quad(91)$ & $56 \quad(86)$ \\
\hline & $50 \quad(74)$ & $46 \quad(71)$ \\
\hline Inhaled steroids & $56 \quad(82)$ & $43 \quad(66)$ \\
\hline Ipratropium & $42^{\star}(62)$ & $27 \quad(42)$ \\
\hline Oral steroids & 33 (49) & 24 (37) \\
\hline Nebuliser & $19 \dagger(28)$ & $8 \quad(12)$ \\
\hline Oxygen & $2 \quad(3)$ & $3 \quad(5)$ \\
\hline Antibiotics & $54 \ddagger(79)$ & $34 \quad(52)$ \\
\hline
\end{tabular}

$\star \chi^{2}=5.45, \mathrm{df}=1, \mathrm{p}=0.02 ; \dagger \chi^{2}=5.02, \mathrm{df}=1, \mathrm{p}=0.03 ; \ddagger \chi^{2}=10.91, \mathrm{df}=1, \mathrm{p}=<0.001$.

changes were not significant. The changes were greater for the intervention than the nonintervention group but not significantly so. The step test showed a significant deterioration in both groups. The values are shown in table 2 ; the sign of the change indicates the direction of change, a positive sign denoting improvement and a negative sign deterioration.

There was a slight improvement in the total Sickness Impact Profile score in the intervention group and a deterioration in the nonintervention group. There was some improvement in the physical and psychosocial Sickness Impact Profile scores in both groups. The physical score was the only handicap index to show a significantly greater improvement in the intervention group.

At the start of the study $17(23 \%)$ in the intervention group and $14(18 \%)$ in the nonintervention group scored 11 or more on the

Table 4 Use of services during the study

\begin{tabular}{|c|c|c|c|}
\hline & Intervention group & Non-intervention group & Significance \\
\hline \multicolumn{4}{|c|}{ Outpatient attendances } \\
\hline & $\begin{array}{l}n=68 \\
\text { No }(\%)\end{array}$ & $\begin{array}{l}\mathrm{n}=65 \\
\text { No }(\%)\end{array}$ & \\
\hline 0 & $1(1)$ & $5(8)$ & \\
\hline 1 & $2(3)$ & 2 (3) & \\
\hline 2 & $8(12)$ & $10(15)$ & \\
\hline 3 & $7(10)$ & 7 (11) & \\
\hline 4 & $10(15)$ & $10(15)$ & \\
\hline$\geqslant 5$ & $40(59)$ & $31(48)$ & \\
\hline Mean & 5 & 5 & \\
\hline \multicolumn{4}{|c|}{ Home consultations with general practitioner $\star$} \\
\hline & $\begin{array}{l}n=60 \\
\text { No }(\%)\end{array}$ & $\begin{array}{l}\mathrm{n}=56 \\
\text { No }(\%)\end{array}$ & \\
\hline 0 & $39(65)$ & $41(73)$ & $\chi^{2}=1 \cdot 0$ \\
\hline 1 & $8(13)$ & $5(9)$ & $\mathrm{df}=2$ \\
\hline$\geqslant 2$ & $13(22)$ & $10(18)$ & $p=0.61$ \\
\hline \multicolumn{4}{|c|}{ Surgery consultations with general practitioner ${ }^{\star}$} \\
\hline & $\begin{array}{l}\mathrm{n}=60 \\
\text { No }(\%)\end{array}$ & $\begin{array}{l}\mathrm{n}=56 \\
\text { No }(\%)\end{array}$ & \\
\hline 0 & $15(25)$ & $11(20)$ & $\chi^{2}=6.96$ \\
\hline 1 & $3(5)$ & $12(21)$ & $\mathrm{df}=2$ \\
\hline$\geqslant 2$ & $42(70)$ & $33(59)$ & $\mathrm{p}=0.03$ \\
\hline \multicolumn{4}{|c|}{ Admissions to hospital } \\
\hline & $\begin{array}{l}\mathrm{n}=68 \\
\text { No }(\%)\end{array}$ & $\begin{array}{l}\mathrm{n}=65 \\
\text { No }(\%)\end{array}$ & \\
\hline 0 & $56(82)$ & $51(79)$ & $\chi^{2}=0.45$ \\
\hline 1 & $6(9)$ & 8 (12). & $\mathrm{df}=2$ \\
\hline$\geqslant 2$ & $6(9)$ & $6(9)$ & $\mathrm{p}=0.80$ \\
\hline
\end{tabular}

*Eight patients from the intervention group and nine patients from the non-intervention group did not record the information on the diary cards. anxiety scale and eight $(11 \%)$ and three $(4 \%)$ scored 11 or more on the depression scale (that is, had an anxiety state or depression severe enough to warrant treatment). At the end of the study $10(15 \%)$ patients in the intervention group and nine $(14 \%)$ in the non-intervention group scored 11 or more for anxiety, and three in both groups scored 11 or more for depression. The improvement in anxiety scores in the intervention group was significant. Although the intervention group tended to fare better than the non-intervention group in terms of psychological indices, none of the differences was significant.

\section{MANAGEMENT OF PATIENTS}

Antibiotics, nebulised salbutamol and ipratropium were prescribed more frequently to the intervention group during the study than to the non-intervention group (table 3 ). There were no significant differences in the frequency of outpatient attendance and hospital admissions during the study year between the two groups. The mean number of outpatient attendances was five in both groups. Twelve patients from the intervention group and 14 from the non-intervention group were admitted during the study year; their mean length of stay was similar, five days for both groups. Patients supervised by the respiratory health worker were likely to be seen more frequently by their general practitioner than those not supervised (table 4).

During the study the respiratory health worker was concerned in the treatment of 52 chest infections, 18 episodes of decompensating cor pulmonale, and 16 acute exacerbations of airflow obstruction.

PREDICTORS OF CHANGE IN HANDICAP SCORE

Three independent variables-the depression score, the six minute walking distance, and the paced step test score-together accounted for $31 \%$ of the variance in the total Sickness Impact Profile score (multiple stepwise regression with entry set at $\mathrm{p}=0.05)$. The $\mathrm{FEV}_{1}(\%$ pred), the six minute walking distance, the depression score, and the anxiety score accounted for $41 \%$ of the variance in the physical Sickness Impact Profile score. The depression score and the step test score accounted for $22 \%$ of the variance in the psychosocial Sickness Impact Profile score.

\section{SASTISFACTION WITH SERVICE}

There was little difference in the level of satisfaction with the service provided between the two groups. Sixty $(88 \%)$ of the 68 patients in the intervention group and $51(78 \%)$ of the 65 in the non-intervention group were very satisfied with their care. Forty one $(60 \%)$ in the intervention and $43(66 \%)$ in the non-intervention group thought that they had been given sufficient information on their chest condition and $59(87 \%)$ and $56(86 \%)$ thought that they used their medication appropriately.

\section{Discussion}

Overall the patients supervised by the res- 
piratory health worker had changes in their indices of impairment, disability, and handicap over the 12 months similar to those of the control group. There were, however, significant differences in the perception of physical capabilities as measured by the physical Sickness Impact Profile, in the medication prescribed, and in mortality.

The number of patients who died was small but patients looked after by the respiratory health worker appeared to have a better chance of survival. This apparently protective effect was associated with more drug prescriptions, more general practitioner attendances, but not increased hospital outpatient or inpatient attendances. The difference in mortality results could be one explanation for the apparently minimal effect that the respiratory health worker had on morbidity. Because patients looked after by the respiratory health worker were less likely to die the remaining patients had more severe disease, which might have masked any improvement in levels of impairment and subsequent disability and handicap. This explanation is supported by the finding that when the Sickness Impact Profile scores of survivors only are compared at the start of the study the survivors in the intervention group had higher total, physical, and psychosocial Sickness Impact Profile scores than those in the non-intervention group (all significant at the $1 \%$ level), which represents more severe disease. Further support is found in the tendency for the indices of impairment in the intervention group to show greater deterioration (reflecting more severe disease), in contrast to the disability and handicap indices, which improved more in this group.

Three further factors, however, need to be considered in the interpretation of the "quality of life" indicators. The first is the power of the study to identify a difference if it existed. The number of patients in this study allows $80 \%$ certainty that a difference in Sickness Impact Profile scores of about 4 would be identified. This magnitude of difference is of the same order as the difference between the survivors in the two groups at the start of the study. The second issue is whether the instruments used are valid. Although the Sickness Impact Profile has been well validated in describing populations, more recently doubts have been raised about its ability to describe change within an individual over time. ${ }^{22}$ This possibility is being investigated further. The last question, perhaps of greater relevance, is whether there is bias in the study design that militates against the achievement of a difference between the two groups. The study was designed to assess the "effectiveness" rather than the "efficacy" of the respiratory health worker, so the clinicians were not given specific instructions regarding changes to their clinical practice. As it was impossible to blind the doctors to the fact that patients were or were not receiving the care of the respiratory health worker they may have compensated in their care for patients in the non-intervention group, which would minimise the potential for improvement. In addition, one year may be too short a time period in which to bring about a significant change in a chronic disorder.

The findings in this study are compatible with the hypothesis, put forward by Cockcroft et al, that increasing care may result not in prevention of deterioration of health and reduced expenditure to the medical service but in the prolongation of survival in the frail and perhaps in the group as a whole. ${ }^{9}$ In so far as costs to the NHS are represented by patients' attendances and drug bills, patients looked after by the respiratory health worker in this study appeared to have incurred more costs for the Family Health Services Authority, though inpatient and outpatient costs were similar apart from the respiratory health worker's salary. It is difficult to establish with certainty whether this is a reflection of the fact that patients were more sick and required more treatment or of the ability of the respiratory health worker to identify more treatable episodes, or was due to better recording of treatment on the diary card by the patients looked after by the respiratory health worker. Doctors during this study did not change their practice to judge by the number of outpatient attendances, so the costs probably relate to an additional rather than an alternative service.

An important role of this type of evaluation is to identify which aspects of intervention lead to prolongation of life and which to improvement in wellbeing. Predictors of mortality in patients with respiratory disease have been well documented. The most important are the age of the patient and the severity of $\mathrm{FEV}_{1}$ impairment, ${ }^{18}$ findings that are confirmed in this study. When the predictors of the change in handicap scores are assessed, however, different patterns emerge, anxiety and depression playing an important part in determining the degree of change in the handicap score. Perhaps attention to these aspects of care rather than concentration on the medical model of disease would benefit the patient suffering with chronic disease more. ${ }^{23}$ The Sickness Impact Profile scores in this study were similar to those seen in a group of patients with angina ${ }^{25}$ but less severe than those of patients with hypoxaemic lung disease who were recruited in the Nocturnal Oxygen Therapy Trial (NOTT) ${ }^{26}$ or the Intermittent Positive Pressure Bronchodilator Trial (IPPB). ${ }^{27}$ These levels were between 20 in the NOTT study and 16 (SD 11) in the IPPB study. In all, 31 patients (23\%) scored 11 or more on the anxiety scale-that is, warranting treatment-and 11 patients $(8 \%) 11$ or more on the depression scale. This is similar to rates obtained in oncology outpatients. ${ }^{28}$

Respiratory health workers and other nurse specialists appear to be increasing in popularity. ${ }^{29}$ This study has assessed the effect of only one respiratory health worker and the other British published study used two, so it may be premature to extrapolate to all respiratory health workers. This study does, however, provide a useful model for health care evaluation in chronic disease. It suggests that an intervention may improve the effectiveness of a service in prolonging life but at increased cost (at least initially) to the health service. 
Whereas each individual receives some additional benefit, in the community the intervention is likely to result in a group of patients with more severe handicap. The contracts for respiratory services in the future will be supposedly based on effectiveness as well as cost. This study highlights the difficulties in interpreting clinical effectiveness for a chronic disease in terms of outcome. It should be attempted, however, to prevent cost becoming the predominant factor.

C M B was supported by a grant from the King's Fund. Drs N T Cooke and J A Lasserson, St Helier Hospital, are thanked for allowing us to study patients under their care. We thank Dr Martin Bland for his comments on the statistical analysis and Professor Ross Anderson for his advice on the study design and for his comments on the paper. Mrs Emma Wheeler is especially thanked for her help with the organisation of the study. The manuscript was typed by Margaret Reverand.

1 Martin J, Meltzer H, Elliot D. The prevalence of disability among adults. OPCS surveys of disability in Great Britain, Report 1. London: HMSO, 1988.

2 Dean M. Community care unveiled at last. Lancet 1989;ii: 1287-88

3 McCarthy M. Cutting the cake: government spending plans for 1986-9. $B M J 1986 ; 292: 840-2$.

4 King's Fund. Facilitating innovation in community care. London: King's Fund, 1987.

5 Burke-Masters BM. The autonomous nurse practitioner: an answer to a chronic problem of primary care. Lancet 1986;i:1266.

6 Cintron G, Bigas C, Linares E, Aimda JM, Hermandez E. Nurse practitioner role in a chronic congestive heart failure clinic: in-hospital time, costs, and patient satisfaction. Heart and Lung 1983;12:237-40.

7 College Committee on Thoracic Medicine. Disabling chest disease: prevention and care. JR Coll Physicians Lond 1981:2:3-19.

8 Royal College of Physicians. Physical disability in 1986 and beyond. JR Coll Physicians Lond 1986;3:160-94.

9 Cockcroft A, Bagnell P, Heslop A, Andersson N, Heaton R, Bathlone $\mathrm{J}$, et al. Controlled trial of respiratory health worker visiting patients with chronic respiratory disability. $B M J$ 1987;294:225-8.

10 Bergner M, Hudson LD, Conrad DA, Patmont CM, Mcdonald G, Perrin EB, et al. The cost and efficiency of home care for patients with chronic lung disease. Med Care 1988;26:566-79.
11 World Health Organisation. International classification of impairment, disabilities and handicaps. Geneva: WHO, 1980

12 Butland RJA, Pang J, Gross ER, Woodcock AA, Geddes DM. Two, six and 12 minute walking tests in respiratory disease. $B M J$ 1982;284:1607-8.

13 Swinburn CR, Wakefield JM, Jones PW. Performance, ventilation, and oxygen consumption in three different types of exercise test in patients with chronic obstructive airways disease. Thorax 1988;40:581-6.

14 Medical Research Council. Definition and classification of chronic bronchitis for clinical and epidemiological purposes. Lancet 1965;1:775-9.

15 Zigmund AS, Snaith RP. The hospital anxiety and depression scale. Acta Psychiatr Scand 1983;67:361-70.

16 Bergner M, Bobbit RA, Carter WB, Gilson BS. The Sickness Impact Profile: development and final revision of a health status measure. Med Care 1981;19:787-805.

17 Gardner MJ, Altman GD. Confidence intervals rather than $p$ values: estimation rather than hypothesis testing. $B M J$ 1986;292:746-8.

18 Krzyzanowski $M$, Wysocki $M$. The relationship of thirteen years mortality to ventilatory impairment and other respiratory symptoms: the Cracow study. Int J Epidemiol 1986;15:56-64.

19 Hosmer DW, Lemeshaw S. Applied logistic regression. New York: Wiley, 1989.

20 Jones PW, Baveystock CM, Littlejohns P. Relationship between general health measured with the sickness impact profile and respiratory symptoms, physiological measures and mood in patients with chronic airflow limitation. $\mathrm{Am}$ Rev Respir Dis 1989;140:1538-43.

21 Cotes JE. Lung function: assessment and application in medicine. 4th ed. Oxford: Blackwell, 1979.

22 MacKenzie CR, Charlson ME, DiGroia D, Kelley K. Can the Sickness Impact Profile measure change? An example of scale assessment. J Chronic Dis 1986;39:429-38.

23 Dudley DL, Glaser EM, Jorgenson BN, Logan DL. Psychosocial concomitants to rehabilitation in chronic obstructive pulmonary disease. Chest 1980;77:544-51.

24 Rutter BM. The prognostic significance of psychological factors in the management of chronic bronchitis. Psychol Med 1979;9:63-70.

25 Watte SR, Rosser RM, eds. Quality of life: assessment and application. Lancaster: MTP, 1987:267-77.

26 Nocturnal Oxygen Therapy Trial (NOTT) Group. Continuous or nocturnal oxygen therapy in hypoxaemic chronic obstructive lung disease. Ann Intern Med 1980;93:391-8.

27 Intermittent Positive Pressure Trial Group. Intermittent positive breathing therapy of chronic obstructive pulmonary disease. Ann Intern Med 1983;99:612-20.

28 Seensky T, Dermehy M, Gilbot A, Begent R, Newlands E, Rustin G, et al. Physicians' perception of anxiety and depression among their outpatients: relationships with patients and doctors satisfaction with their interviews. $J R$ Coll Physicians Lond 1989;23:33-7.

29 Partridge MR. Respiratory nurse specialists. Respiratory Disease in Practice 1987;4:7. 